\title{
Aspectos de autoridad y poder en las ceremonias de canonización de Ignacio de Loyola y Francisco Javier en Portugal

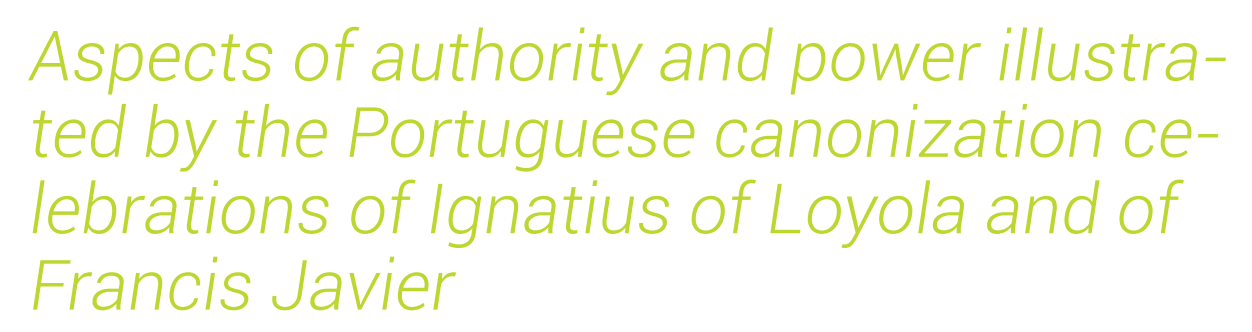

\section{Cristina Osswald}

Universidade Nova de Lisboa

Departamento de História de Arte

Faculdade de Ciências Sociais e Humanas

Av. de Berna, 26-C

1069-061 Lisboa, PORTUGAL

CITCEM- Universidade do Porto

Centro de Investigação Transdisciplinar «Cultura, Espaço e Memória (CITCEM)»

Faculdade de Letras da Universidade do Porto

Via Panorâmica, s/n, 4150-564 Porto, PORTUGAL

osswaldcristina@gmail.com

[Hipogrifo, (issn: 2328-1308), 1.1, 2013, pp. 43-55]

Recibido: 17-02-2013 / Aceptado: 16-03-2013

DOI: http://dx.doi.org/10.13035/H.2013.01.01.05

Resumen. La canonización del fundador de una orden religiosa constituye un hito en la afirmación de la autoridad de dicha orden. En lo que respecta a la Compañía de Jesús, se trató además de una canonización doble. Este hecho, muy poco común, demuestra el poder que la Compañía de Jesús poseía en la Curia Papal en la época y explica su claro propósito de celebrar la idea de glorificación. En lo tocante a la escenografía se trataba, por encima de cualquier otra cosa, de enaltecer el Triunfo de la Compañía a través del recurso a figuras alegóricas que representaban la Religión, la Fama, el Honor o la Pompa. Además, la iconografía de estas fiestas encuadró a sus dos primeros santos en la historia de la Compañía y con ello elogiaba a toda la orden. Así, la escenografía jesuita portuguesa rindió homenaje a 
los dos beatos, a los primeros compañeros y también a miembros de la Compañía muertos por su fe por todo el mundo y además se ponía de relieve sus principales devociones, características (su carácter universal) y actividades tales como su actividad misionera y su actividad de enseñanza. En la época moderna solía suceder que la canonización de una determinada figura estaba íntimamente relacionada con el poder político. Por tal razón, las fiestas portuguesas exaltaron con gran vigor sentimientos de nacionalismo en plena época de unión ibérica. Para transmitir estos objetivos, los organizadores no dudaron en recurrir a todos los instrumentos festivos propios de la época barroca (poesía, teatro, danza, música y artes visuales). Es decir, se llevó a cabo una serie de festejos muy lujosos y grandiosos que incluían espectáculos de luces, sonido, color y olor (cabe mencionar la colocación en el interior de las iglesias de recipientes con perfumes).

Palabras clave. Ignacio de Loyola, Francisco Javier, festividades de canonización, Portugal, autoridad, poder.

Abstract. The canonization of the founder of a Catholic religious order constitutes a milestone in the affirmation of authority by that order. As concerns to the Society of Jesus, it was a double canonization. Such an uncommon fact as this, clearly both demonstrates the power the Society had at the time at the Curia, and explains its intention of celebrating the auto-glorification. Its scenography, thus, aimed more to praise the triumph of the Society of Jesus through the use of allegorical figures such as Religion, Fame, Honour or Pomp, than anything else. The iconography of such festivities framed the first Jesuits saints within the history of the Society. Thus, the Portuguese jesuits paid homage, by means of the staging, to the beatified ones, the first jesuits and the martyrs. Moreover, the set pointed out its main devotions, characteristics and activities such as missionary work and teaching activities. Often canonizations of a certain figure were intimately related to political power in Early Modern Time. Therefore, Portuguese Jesuit festivities exalted, with a great vigour, feelings of nationalism during the Iberian Union's time. In order to transmit the various aims, the organizers did not hesitate to use all Baroque celebrative resources (poetry, theatre, dance, music and visual arts). In other words, particularly luxurious and grandiose celebrations, including light, sound, colour, and odour spectacles or events (reference be made to the vases with perfume inside the churches) took place by that time.

Keywords. Ignatius of Loyola, Francis Xavier, Canonization Festivities, Portugal, Authority, Power.

\section{LOS «THEATRI JESUITII»}

El siglo XVII fue el siglo de oro de la Compañía de Jesús, o sea de su afirmación definitiva como una de las principales órdenes religiosas de la Iglesia Católica en la época moderna. 
Ignacio de Loyola y Francisco Javier fueron canonizados con Teresa de Ávila, Felipe Neri e Isidoro de Sevilla el día 12 de marzo de 1622 por el Papa Gregorio XV. Esta canonización fue la más numerosa realizada hasta el momento’.

La canonización del fundador de una orden religiosa constituye un hito en la afirmación de la autoridad de dicha orden. En lo que respecta a la Compañía de Jesús, se trató además de una canonización doble. Este hecho, muy poco común, demuestra el poder que la Compañía de Jesús poseía en la Curia Papal en la época. En el origen de tal acontecimiento, la canonización en el último momento de Francisco Javier, conocido ya en vida por sus capacidades taumatúrgicas, suele ser interpretada como compensación de la falta de milagros por parte de Ignacio de Loyola.

La noticia del «dichoso evento» llegó el 14 de abril de 1622 a Lisboa, o sea, casi un mes después de la canonización en Roma que se había llevado a cabo el 19 de marzo. Las ceremonias portuguesas se iniciaron en Lisboa el día 31 de julio, que es el día de San Ignacio, y se extendieron a la totalidad de la octava del santo. Además de en Lisboa, este evento se celebró en todas las localidades donde los jesuitas administraban instituciones, o sea, no solo en las principales ciudades del Reino (Oporto, Coímbra, Évora), sino también en los pueblos de Vila Viçosa e incluso en S. Fins (pequeño pueblo en la Serra de la Estrella).

En estos ambiciosos programas festivos, que eran ceremonias religiosas y al mismo tiempo espectáculos de diversión de alta carga sensorial, los jesuitas recurrieron a todos los recursos artísticos a su disposición para concebir un espectáculo lo más grandioso posible (poesía, teatro, danza, música y artes visuales). Es decir, se llevó a cabo una serie de festejos muy lujosos y grandiosos que incluían espectáculos de luces, sonido, color y olor (cabe mencionar la colocación en el interior de las iglesias de recipientes con perfumes).

Durante algunos días, las ciudades y los pueblos se transformaron en auténticos theatri jesuitii a través del montaje de arcos triunfales y altares, de la preparación de las calles y de las plazas para el paso de los desfiles y procesiones, de máquinas o carros triunfales, con decoración de banderolas, gallardetes, tapices, listones de delicadas y costosas telas, además de la fijación de carteles, la realización de espectáculos teatrales y de lecturas poéticas, de diversiones como danzas, torneos, corridas de toros y otros juegos, «tableaux vivants» de figuras y animales vivos, paradas militares $y$, al anochecer, encendido de luminarias y fuegos artificiales$^{2}$. En algunos momentos, esta rica y variada iconografía pretendía suscitar un sentimiento de temor entre los espectadores, por ejemplo, a través del desfile de figuras monstruosas y de máquinas y castillos, que eran incendiados para terminar los festejos nocturnos.

La canonización y, en menor grado, la beatificación (las ceremonias de 1622 también estuvieron dedicadas a la beatificación del jesuita italiano Luis Gonzaga el

1. Osswald, 2007, p. 261

2. Parece que solo en las casas jesuíticas de Portugal y en Toledo se usaron animales vivos durante las fiestas hagiográficas (Arellano, 2006, p. 244). 
año anterior) son siempre momentos de afirmación del poder y de la autoridad de la Iglesia Católica como tal. Por tal razón, al igual que en otras partes, las ceremonias portuguesas incluyeron la participación activa de las principales autoridades eclesiásticas. Todas las órdenes religiosas presentes en las distintas localidades donde se realizaron las festividades se encargaron además de la celebración de misas y de la predicación de sermones durante uno de los días de la octava.

El lujo que ostentaron las fiestas de 1622 en Portugal solo fue posible gracias al financiación por parte de la Corona y de las élites locales. El patronazgo generoso tuvo reflejos en la iconografía. Para agradecer la generosidad de la Condesa de Vidigueira que costeó la decoración de la Iglesia de San Roque, en Lisboa, los reposteros de la nave de la dicha iglesia lucían bordados los escudos de la familia de la donante, mostrando el ilustre linaje de la patrona ${ }^{3}$.

Sin embargo, la masiva participación popular también era un aspecto fundamental en estas celebraciones (las festividades comenzaban con un repique general de campanas convocando a los habitantes de la localidad). Como era habitual en las fiestas barrocas, el pueblo era invitado a asistir no solo como mero espectador, sino como ejecutante. Aunque pueda parecer una exageración, en la Relaçam Geral das festas se dice que a la Iglesia de San Roque, en Lisboa, acudieron personas que vivían a más de treinta leguas de distancia. Durante la procesión fue necesaria la intervención de la Guardia Real de los Tudescos, debido a la presión que ejercía la multitud ${ }^{4}$. Además de iglesias, calles y plazas repletas de espectadores, hay que sumar en las ciudades de Lisboa, Évora, Braganza y Oporto el encendido de luminarias en muchas casas particulares en cuanto se difundió entre la población la feliz noticia ${ }^{5}$.

\section{LA CELEBRACIÓN DE LOS DOS PRIMEROS SANTOS DE LA COMPAÑÍA: IGNACIO DE LOYOLA Y FRANCISCO JAVIER}

Además de ser representados juntos, los santos podían ser venerados con otros santos o figuras importantes de la Iglesia. Por ejemplo, en el primer aplauso de la principal procesión de Lisboa (esta procesión estaba dividida en ocho aplausos), el cual estaba dedicado a la penitencia de Ignacio y Javier, ocho figuras de santos penitentes a caballo desfilaron delante del carro triunfal ${ }^{6}$.

Otras veces, los santos y sus virtudes eran representados separadamente, por ejemplo a través de carros individuales como sucedió en Évora? También en Évora, los primeros tres actos de la tragicomedia estuvieron dedicados a Ignacio de Loyola, mientras que los tres siguientes fueron consagrados a Francisco Javier ${ }^{8}$.

3. Relaçam Geral das Festas que fez a Companhia de Jesús na Província de Portugal, na canonização dos gloriosos Sancto Ignacio, \& S. Francisco Xavier Apostolo da India Oriental no ano de 1622, fol. 4.

4. Relaçam Geral das Festas, fols. 7 y 8v., y Torres Olleta, 2009, pp. 300-301.

5. Relaçam Geral das Festas, fols. 2, 76 y $138 \mathrm{v}$.

6. Relaçam Geral das Festas, fols. 16r-16v, 19r-19v, y Arellano, 2009a, p. 34.

7. Relaçam Geral das Festas, fols. 94v-99.

8. Relaçam Geral das Festas, fol. $62 \mathrm{v}$. 
En general, las festividades de canonización son importantes vehículos de creación de modelos de emulación para los creyentes. Por tal razón, en la iconografía de estas fiestas, aparecen episodios centrales de la hagiografía de los dos santos. Las ceremonias organizadas por los padres de San Roque terminaron precisamente con el incendio del castillo de Navarra donde Ignacio fue herido 9 . En Coímbra, el segundo carro triunfal ilustraba la conversión de Ignacio. Este tema fue también reproducido en Funchal. Por su parte, dos de los más famosos episodios javerianos, el del milagro del cangrejo y el de las disputas con el Rey del Bungo, fueron temas popularizados por la iconografía de las fiestas portuguesas. Por ejemplo, en Oporto y en la Isla Tercera se organizaron danzas muy curiosas de cangrejos ${ }^{10}$.

Al igual que en otras ceremonias de canonización jesuitas, en algunas de las fiestas portuguesas se pudo contemplar una escenografía espectacular de temas naturales (en especial, dedicada a los temas marítimos en estrecha relación con Francisco Javier, como demuestran las naos y los carros específicamente consagrados a él) mitológicos y celestes ${ }^{11}$.

Comenzando por Lisboa, en «el quinto aplauso hacían el acompañamiento los cuatro elementos [de la Reina Santa Isabel], sujetos de muchos de los milagros de los santos» ${ }^{12}$. Por su parte, la iconografía de las fiestas de Braganza ilustra la importancia que la mitología tuvo en las fiestas portuguesas de 1622. En esta ciudad de Braganza, durante el segundo día de las celebraciones, desfiló una figura de un atlante con el globo del mundo en las espaldas (Francisco Javier), el cual iba precedido por una curiosa danza de enanos vestidos con «calças indiáticas», representando a los pueblos indios u orientales convertidos por el santo ${ }^{13}$. La misma figura del atlante representaba también a Ignacio de Loyola en un cuadro pintado en la popa del carro galeón dedicado a este santo, mientras que, en el segundo aplauso de Lisboa, Hércules con el mundo sobre el carro triunfante mostraba el celo de los dos santos en la conversión de toda la Humanidad.

En lo que respecta a la cosmología, en el octavo aplauso de Lisboa la Gloria estaba también acompañada por elementos cósmicos (Luna, Mercurio, Sol, Marte, Júpiter, Saturno). En Braga, entre las figuras que acompañaban el carro con el Triunfo de la Sagrada Cruz, se exhibieron Marte, Júpiter y Saturno. Sobre el carro de la Gloria de los dos santos en las fiestas de Oporto fue colocado un globo con el sistema cósmico y el zodiaco ${ }^{14}$.

9. Relaçam Geral das Festas, fols. 6 y 9, y Festas en Lisboa de 1622, fol. 350

10. Relaçam Geral das Festas, fols. 81 v-86, y Arellano, 2009a, p. 44.

11. El motivo marino destacó en las danzas de Coímbra que acompañaban a Francisco Javier, donde los inevitables tritones, imitando peces (vestían escamas y tenían cabezas cubiertas de limos marinos, además de llevar algunos mariscos en la mano derecha), ejecutaban una curiosa y artificiosa danza. Les seguía el Dios Palemón montando una monstruosa ballena y luego Neptuno sentado sobre una concha tirada por dos caballos marinos de «notable grandeza» (Relaçam Geral das Festas, fols. 58v-59).

12. Relaçam Geral das Festas, fol. 32.

13. Relaçam Geral das Festas, fols. 140v-141v.

14. Relaçam Geral das Festas, fols. 43-44, 116 y 185. 


\section{LA CELEBRACIÓN DE LA COMPAÑÍA DE JESÚS}

La canonización de miembros de una orden religiosa es un momento culminante de autoridad, entendida como glorificación de dicha orden, en este caso, de la Compañía de Jesús. Esta noción de triunfo es, por lo tanto, central en el ritual de las festividades de canonización. En lo tocante a la escenografía se trataba, por encima de cualquier otra cosa, de enaltecer el Triunfo de la Compañía latum sensum. Para ejemplificar esta afirmación basta con destacar que, durante la procesión de Vila Viçosa, se pudo ver una figura sentada en un trono muy bien ornado y que pretendía simbolizar a la Compañía. También en la provincia del Alentejo, en la ciudad de Portalegre, el primer carro que salió era la alegoría de la Compañía de Jesús ${ }^{15}$.

Para mostrar el triunfo de la Compañía de Jesús se recurrió a figuras alegóricas que representaban la Religión, la Fama, el Honor o la Pompa. Estas figuras podían aparecer abriendo las fiestas. En Lisboa, para comenzar los festejos, la Religión de la Compañía, representada como figura trágica, abrió la mascarada, saliendo de la Casa Profesa de San Roque. Por su parte, en la Isla Tercera, la propia noticia de la canonización fue difundida entre la población por los estudiantes a caballo, acompañados de una figura de la Fama'16.

En el primer acto de la Tragicomédia de Évora, Ignacio se ofrece a la figura del Honor para combatir a los franceses, mientras en el cuarto acto la Fama informa a los pueblos orientales de la próxima llegada de Francisco Javier. El tercer carro triunfal de la procesión de Coímbra: «se intitulava da Pompa, ou Honra Humana, e representava a que fazia a igreja assim militante como triunfante a Sancto Ignacio; em sua canonizaçâo» ${ }^{17}$.

Durante la misma procesión, las figuras alegóricas del Honor y de la Fama conducían el último carro con los santos en la gloria ${ }^{18}$.

En el contexto profundamente simbólico o alegórico que enmarca las festividades de 1622, la victoria del bien sobre el mal fue representada como victoria militar y elemento esencial en la lucha y triunfo de la fe sobre la herejía y el paganismo. A las luchas de origen medieval entre cristianos y moros hay que sumar las sugestivas y con frecuencia espectaculares composiciones de gran complejidad iconográfica que incorporaban hidras apocalípticas, cocodrilos, tortugas o rinocerontes en la visualización del combate de la Fe y de la Religión contra la idolatría y la herejía ${ }^{19}$.

En las fiestas portuguesas de 1622 se siguió la práctica común a las fiestas hagiográficas jesuitas de encuadrar a los santos o beatos en la historia de la Compañía y con ello elogiar a toda la orden. Además de los personajes principales, Ignacio

15. Relaçam Geral das Festas, fols. 150 y 208

16. Relaçam Geral das Festas, fols. 6r-6v, 208 y $212 \mathrm{v}$

17. Relaçam Geral das Festas, fol. 63v

18. Extracto da tragicomedia intitulada Santo Ignacio: a materia he sua milicia, conversão, estudos, confirmação da Companhia, \& mais progressos ate sua morte, \& canonização: representada na Universidade \& Collegio da Companhia de Jesu da Cidade daEvora, aos de Junho de 62, s/fol.

19. Ver el sugestivo capítulo «La guerra del bien y del mal» en Arellano, 2009a, pp. 36-41. 
de Loyola y Francisco Javier, la escenografía jesuita portuguesa rindió homenaje a los dos beatos, a los primeros compañeros y también a los compañeros muertos por su fe por todo el mundo ${ }^{20}$.

En cuanto a los beatos, hay que mencionar las fiestas de Lisboa y de Coímbra, donde las celebraciones en honor de Luis Gonzaga consistieron en fuegos e invenciones durante la víspera y en el día de este beato. El beato tuvo un carro propio en Évora, en Braganza y en Oporto ${ }^{21}$. En esta última ciudad se decidió consagrar un día a su celebración y, además, dar un premio al mejor soneto dedicado a Gonzaga, que tenía que estar compuesto en italiano por ser ésta su nacionalidad ${ }^{22}$. En Braga, el retablo del altar mayor de la iglesia jesuita fue adornado con los retratos de los santos y también del beato ${ }^{23}$.

Por su parte, en Villa Viçosa, una figura del otro beato jesuita, Estanislau Koska (1605), desfiló a continuación de las figuras que representaban las provincias jesuitas de Polonia y Lituania donde el beato había trabajado ${ }^{24}$. En la Isla de Madeira, el primer paso mostraba un escenario con el consistorio papal, además de con los beatos Luis Gonzaga y Estanislau Koska ${ }^{25}$.

Sin embargo, las otras figuras canonizadas con Ignacio y Javier (Felipe Neri, Isidoro de Madrid y Teresa de Avila) fueron relegadas a un lugar secundario en las fiestas jesuitas portuguesas, pues fueron celebradas únicamente en $\mathrm{Braga}^{26}$.

En relación a otros miembros de la Compañía, estas ceremonias honraron a los primeros compañeros (Lisboa) y sobre todo a los miembros muertos por la fe por todo el mundo en una escenografía notable por su variedad ${ }^{27}$.

Los jesuitas montaron las llamadas «galerías de mártires» (conjuntos de retratos mostrando a los mártires todos vestidos del mismo modo, con la palma del martirio en la mano y organizados por fecha y región geográfica, desde los más antiguos hasta los más recientes) en el interior de las iglesias (Braga) o en los atrios y vestíbulos de las instituciones jesuitas (Casa Profesa de San Roque) ${ }^{28}$.

Naos o galeones con figurantes que representaban mártires desfilaron en Lisboa y en Braga. En Évora, en una de las puertas de la ciudad -la Porta de Moura- se representó un cuadro con los mártires de la Compañía vestidos de gala, con estrellas de oro y plata sobre el pecho, flores en la cabeza y las palmas en las

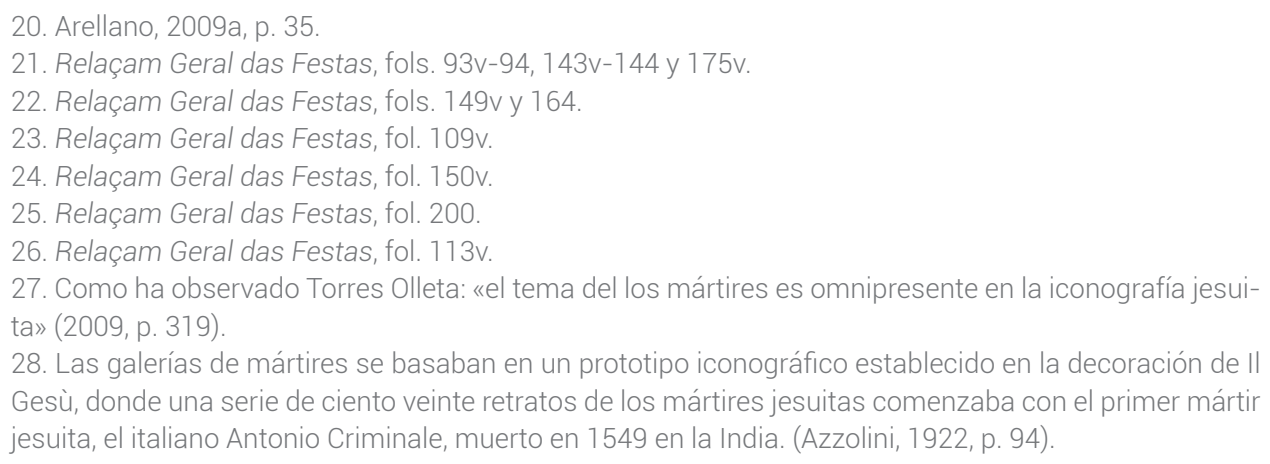


manos. En Funchal, el último paso mostraba un elaboradísimo árbol de mártires de la Compañía culminado por Ignacio de Loyola ${ }^{29}$.

En Braga, en el coro de mártires guiado por el primer protomártir del Cristianismo, San Esteban, fueron destacados los dos mártires jesuitas locales: João Fernandes, uno de los cuarenta mártires de Brasil (1570), y Francisco Aranha, muerto en 1583 en el pueblo de Salsete de Goa, India. Del mismo modo, en Lisboa, en el galeón de la India cargado de mártires, a excepción del inglés Edmund Campion y de sus compañeros muertos en Tyburn, Inglaterra, en 1581, todos los restantes mártires o eran portugueses o habían sido distinguidos con la gloria del martirio en territorios portugueses ${ }^{30}$.

La representación de estas figuras debe ser así entendida como laudatoria para la propia Provincia Portuguesa por su empeño en el progreso general de Compañía. Esta idea ya la podemos encontrar en el prólogo, donde se pude leer que Ignacio nutría un amor especial por la gran observancia religiosa ahí demostrada y por el hecho de que la Provincia Portuguesa era la más antigua provincia jesuita. El Reino de Portugal con sus territorios fue el lugar donde Francisco Javier obró la mayoría de sus acciones maravillosas, circunstancia que se recoge y representa en el galeón javeriano en Braganza, en cuya popa se encontraban las armas portuguesas ${ }^{31}$.

Un tema recurrente en la celebración de la Compañía de Jesús durante las fiestas portuguesas de 1622 fue la devoción al Nombre de Jesús, debido al hecho, bien conocido, de que tal devoción está íntimamente asociada a la designación escogida por Ignacio de Loyola para la orden. Para ejemplificar, en la Iglesia de San Roque, en Lisboa, un hermoso resplandor en plata con rayos en oro y con las letras del Nombre de Jesús de noble terciopelo estaba colgado a lo largo del arco. También en Lisboa, el séptimo y penúltimo carro llevaba un trono o pedestal donde los dos santos tomaban posesión del nombre de Jesús. En Évora, un jinete con un estandarte de damasco y con el Nombre de Jesús en letras de oro abrió la procesión ${ }^{32}$. También podía ser que la figura que representaba a Ignacio fuese el encargado de trasportar el emblema del Nombre de Jesús, como fue el caso durante la procesión de Évora o de Vila Viçosa ${ }^{33}$. En Braga, este emblema del Santísimo Nombre de Jesús remataba dos columnas sobre el retablo ${ }^{34}$. En Vila Viçosa, la figura de la Compañía tenía en la mano derecha la divisa del Santísimo Nombre de Jesús, mientras en Portalegre, la figura de la Compañía lucía la divisa sobre la cabeza ${ }^{35}$.

Curiosamente, fue en la ciudad de Braganza donde los jesuitas locales realizaron una iconografía más rica del Nombre de Jesús. Durante la procesión, la figura de la Compañía llevaba la divisa con un Niño Jesús en oro. A continuación, aparecía un carro con un Ignacio de Loyola (un atlante) con el Nombre de Jesús en las ma-

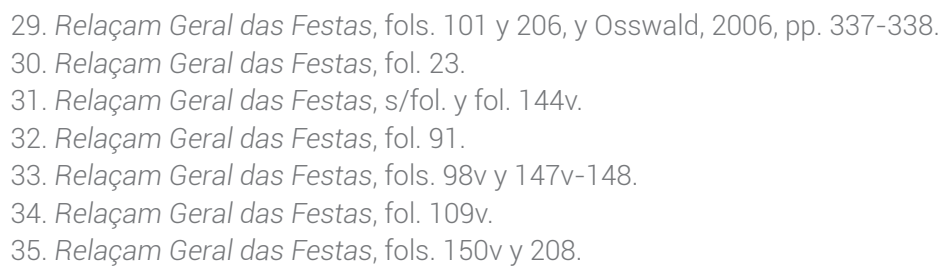


nos. Una idea fundamental de esta iconografía fue representar la vitoria del Nombre de Jesús sobre el mal. Para ello, el mismo carro estaba decorado con tres cuadros de cada lado que formaban escenas de la vitoria del bien sobre el mal (la vitoria de David sobre Goliat, la vitoria de los ángeles sobre los demonios, y, para acabar, Moisés). Las figuras del bien iban acompañadas con la representación del Nombre de Jesús ${ }^{36}$. Pensamos que en el aplauso séptimo de Lisboa se quiso transmitir esta idea recurriendo a la comicidad, pues en el carro triunfal dos diablitos veneraban el Nombre de Jesús y a los dos santos, que aparecían sobre un trono ${ }^{37}$.

El carácter universal de la Compañía de Jesús fue, sin duda, un aspecto realzado por la iconografía de las fiestas portuguesas de 1622. La actividad misionera de la Compañía ofreció a los organizadores de las fiestas la posibilidad de dar alas a la imaginación, creando un lenguaje exótico de una riqueza y variedad difíciles de igualar. Especialmente espectacular fue la hermosa danza de aves representando los cuatro continentes que se realizó en Lisboa ${ }^{38}$. Hay que mencionar, igualmente, el desfile de provincias jesuitas de los distintos continentes, por ejemplo Perú y Brasil en el caso de América, o las cinco provincias africanas más conocidas: Etiopia, Mombaça, Angola, Congo y Cabo Verde ${ }^{39}$. Ahora bien, para abrir la procesión de Vila Viçosa, los jesuitas representaron la idea de la universalidad de la misión de la Compañía a través del desfile de figuras de los continentes seguidas de los cuatro elementos del mundo: «Apos estas cinco principaes partes de mundo, Ceo, Fogo, Ar, Agua, \& Terra, que assi representavão neste muy solenne acompanhamento o mundo todo, pelo qual a fama destes dous Sanctos Patriarchas, tinha levado e dado a conhecer a Companhia de Jesus, de que são Patriarchas» ${ }^{40}$.

La enseñanza fue un tema omnipotente en las festividades portuguesas debido a la importancia de este ministerio para la Compañía de Jesús. Empezando por la referencia a las fiestas que se desarrollaron en Lisboa, se organizó una deslumbrante escenografía mostrando un majestuoso desfile de figuras, que tenían en las manos las armas de las veinte ciudades donde existían universidades jesuitas ${ }^{41}$. Por supuesto, especial relevancia fue dada a los temas de la enseñanza y del saber en las ciudades de Coímbra y en Évora, donde la Compañía tenía universidades. Así en Coímbra el cuarto carro honraba las letras y las armas, pues: «huma y otra alcançou o glorioso Santo Inácio, porque a ambas professou» ${ }^{42}$.

En Évora se desplegó un cuadro delante de la puerta principal de la ciudad que representaba a la universidad con todas las ciencias (teología, filosofía, retórica, humanidad, gramática) y además incorporaba la figuración del Cardinal D. Henrique, fundador de dicha universidad ${ }^{43}$.

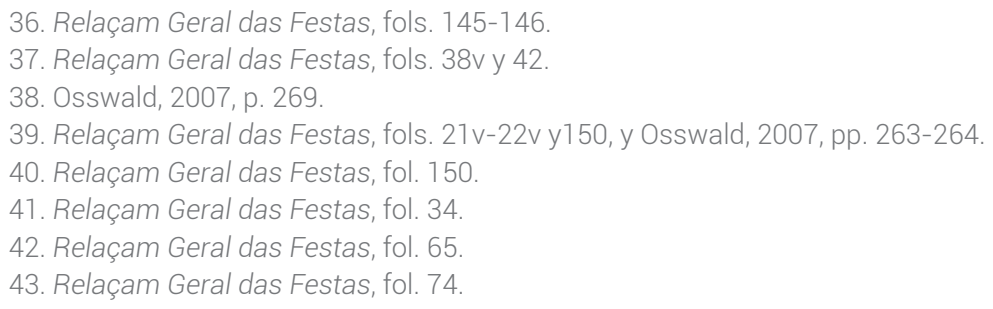




\section{LA AFIRMACIÓN DE LA IDENTIDAD PORTUGUESA}

En la época moderna solía suceder que la canonización de una determinada figura estaba íntimamente relacionada con el poder político. Así, el autor de la relación de las fiestas portuguesas empieza señalando que la canonización de Ignacio de Loyola y Francisco Javier se realizó a instancia de varios miembros de las Coronas Reales. Además de Felipe III y de su mujer, Margarita de Austria, son mencionados los reyes de Francia y los «príncipes cristianos y señores del Imperio» ${ }^{44}$.

Existe además en Roma un chascarrillo según el cual en torno a 1622 se decía en la ciudad que habían sido canonizados cuatro españoles y un santo. Este dicho jocoso sirve para ilustrar la idea de la importancia de España en la Curia Papal en este tiempo, o sea, de la íntima relación entre Roma y España a principios del siglo XVIII5. En lo que se refiere a las ceremonias de 1622 en Portugal, habría que mencionar el desfile de un carro dedicado a santos españoles (San Hermenegildo, Santiago, San Justo, San Pastor y San Lorenzo así como San Vicente) durante las ceremonias de Coímbra ${ }^{46}$.

Sin embargo, la escenografía de estas ceremonias de canonización intentó sobre todo mostrar valores portugueses. Así, en Lisboa y Coímbra, santos portugueses acompañaban a los santos canonizados ${ }^{47}$. Como era característica común a las fiestas de canonización, también en Portugal, una de las modalidades consistió en la personificación de entidades geográficas, regionales, administrativas y accidentes naturales de Portugal. Como ejemplo cabe señalar que, en Oporto, desfilaron máscaras con parroquias de la ciudad (Massarelos, S. João da Foz) y de los pueblos vecinos (Leça do Balio, Matosinhos) ${ }^{48}$. En Lisboa, se organizó una danza de ocho ríos afluentes del Tajo, al igual que en Funchal, donde se puso en escena una hermosa danza de ríos portugueses, mientras que en la Isla Tercera fue organizada una danza de las islas Azores. En Braganza, un jinete que representaba a la ciudad abrió la procesión ${ }^{49}$.

Parece evidente que estas fiestas procuraron reforzar la idea de identidad política portuguesa. Concordamos totalmente con la afirmación de Ignacio Arellano, quien sostiene que: «en una época de unión de las dos coronas, el reino de Portugal refuerza su propia identidad con la exhibición de sus reyes y figuras históricas nucleares en las procesiones de todas las ciudades que celebraran las canonizaciones jesuitas» ${ }^{50}$.

Así, en el preludio del aplauso hecho por la ciudad de Lisboa a los dos santos aparecen diversos jinetes, vistiendo los trajes típicos de su época, que representan a los reyes y a los capitanes que favorecieron en concreto a la ciudad de Lisboa des-

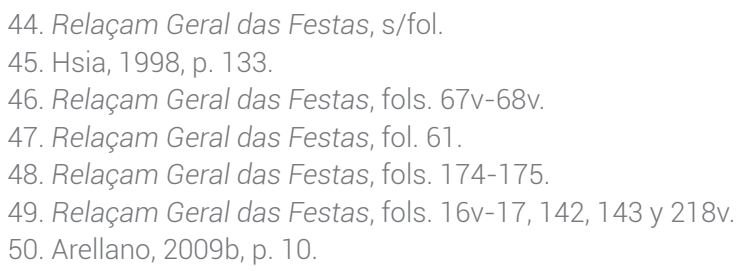


de época romana (Julio César que la habría designado Felicitas Iulia, Ulises que la reedificó), D. Afonso Henriques, D. Dinis y D. João II hasta concluir con D. Manuel I51.

También en Lisboa, en el segundo aplauso, Santa Engracia, mártir portuguesa que gozaba de especial devoción entre los lisboetas desde el siglo XVI, tenía sobre el pecho: «un escudo em oro com as armas de Portugal matizado con perolas e diamantes de tanto valor ${ }^{52}$.

Concluyó el IV aplauso de las mismas fiestas con un carro dedicado a San Teotónio, Prior del Real Monasterio de Santa Cruz de Coímbra, debido al hecho de que D. Afonso Henriques había alcanzado importantes victorias contra los enemigos por intercesión de este religioso ${ }^{53}$. En Évora, durante la procesión, los dos capitanes, Geraldo (un noble que se había ofrecido para tomar Évora a los moros) y Sartorio (el capitán de las tropas romanas estacionadas en Évora), daban los parabienes a Roma por la doble canonización. En Oporto, figuras simbolizando los dos caballeros lusitanos invencibles, Brasilindo y Manidoro, participaron en los torneos ${ }^{54}$.

Por supuesto, el Rey D. João III, por su papel inicial en el desarrollo de la Compañía, fue evocado en las fiestas portuguesas. El autor de la relación de las fiestas justifica la presencia de este rey detrás de las universidades afirmando que él había sido el «padre de las letras, y de la Compañía en estos reinos»" ${ }^{55}$.

Además, el cuarto acto de la tragicomedia de Évora contenía la petición del rey D. João III al Papa y a Ignacio de Loyola para que fueran enviados jesuitas para la conversión de Oriente ${ }^{56}$.

Cabe mencionar también la ilustración de las virtudes de los santos empleando para ello figuras reales en las fiestas de Lisboa. En el segundo aplauso, junto al carro triunfal, iban en primer lugar los dos Infantes D. Henrique y D. Fernando: «filhos del Rey D. João o primero de boa memoria, que perpetuamente conservarão a flor da pureza virginal» ${ }^{57}$.

El aplauso V ilustraba la capacidad taumatúrgica de Ignacio y Javier a través de la figura de «la milagrosa Sancta Isabel Reina de Portugal» ${ }^{58}$.

En varias ceremonias el Imperio Portugués fue motivo central de la escenografía. En Lisboa, dos carros representaron el comercio y la navegación, o sea, los dos pilares del Imperio Portugués. En Coímbra, desfiló una figura representando al

51. Relaçam Geral das Festas, fol. 17.

52. Relaçam Geral das Festas, fol. 25.

53. Relaçam Geral das Festas, fol. $31 \mathrm{v}$

54. Relaçam Geral das Festas, fols. 91v-92, 101, 132 y 170.

55. Relaçam Geral das Festas, fol. 34.

56. Relaçam Geral das Festas, fol. 82.

57. Relaçam Geral das Festas, fol. 26v

58. Relaçam Geral das Festas, fol. 32.

HIPOGRIFO, 1.1, 2013 (pp. 43-55) 
Imperio seguida de figuras alegóricas de las principales ciudades de la India (más exactamente de Asia): Goa, Malaca, Diu y Ormuz ${ }^{59}$.

\section{CONCLUSIONES}

Para terminar, esperamos haber demostrado que los jesuitas portugueses consiguieron trasformar las ciudades y los pueblos donde celebraron la doble canonización en verdaderos theatri jesuitii. Para ello recurrieron a todos los recursos artísticos a su disposición a fin de crear un espectáculo lo más grandioso posible (poesía, teatro, danza, música y artes visuales). En tal empresa fueron decisivas no solo la generosidad de la Corona y de las elites locales sino también la colaboración de las otras órdenes religiosas además de la masiva participación popular.

Al igual que en otras ceremonias de canonización jesuitas, en algunas de las fiestas portuguesas se pudo contemplar una escenografía espectacular de temas naturales (en concreto, la dedicada a los temas marítimos en estrecha relación con Francisco Javier, como demuestran las naos y los carros específicamente consagrados a él), a los que se suman los mitológicos y celestes.

La canonización de miembros de una orden religiosa es un momento culminante de autoridad, entendida como glorificación de dicha orden, en este caso, de la Compañía de Jesús. Para mostrar esta idea, se recurrió a figuras alegóricas que representaban la Religión, la Fama, el Honor o la Pompa. Fueron igualmente destacados los dos beatos, los primeros miembros de la Compañía junto a otros beatos, así como las principales devociones y actividades desarrolladas por los jesuitas.

Además de constituir una celebración de primera importancia para la Iglesia Católica y para la propia Compañía de Jesús, estas fiestas exaltaron sentimientos de nacionalismo portugués en plena época de unión ibérica.

\section{BIBLIOGRAFÍA}

Arellano, Ignacio, «San Francisco Javier en el teatro del Siglo de Oro», en Sol, Apóstol, Peregrino, San Francisco Javier en su Centenario, ed. Ignacio Arellano, Pamplona, Gobierno de Navarra, 2006, pp. 241-265.

- «Enseñanza y diversión en fiestas hagiográficas jesuitas», en Doctrina y Diversión en la Cultura Española y Novohispana, ed. Ignacio Arellano y Robin A. Rice, Madrid/Frankfurt am Main, Iberoamericana/Vervuert, 2009a, pp. 27-54.

- $\quad$ «Vive le roy! El poder y la gloria en fiestas hagiográficas francesas (canonización de San Ignacio y San Francisco Javier, 1622)», en Autoridad y poder en el siglo de oro, ed. Ignacio Arellano, Christoph Strosetzki y Edwin Williamson, Madrid/Frankfurt am Main, Iberoamericana/Vervuert, 2009b, pp. 9-33.

59. Tanto en Lisboa como en Coímbra, la figura mostrando la ciudad de Ormuz llevaba sobre el pecho más oro y piedras preciosas debido al hecho de ser la ciudad más rica en la India. 
Azzolini, Ilario M., «Le immagini dei martiri della Compagnía di Gesù nell addobbo del tempio farnesiano per la canonizzazione del 1622», en La Canonizzazione dei Santo Ignazio di Loiola Fondatore della Compagnia di Gesù e Francesco Saverio Apostolo dell'Oriente, ed. Comitato Romano Ispano per le Centenarie Onoranze, Roma, Grafia Stampa, 1922, pp. 94-99.

Extracto da tragicomedia intitulada Santo Ignacio: a materia he sua milicia, conversão, estudos, confirmação da Companhia, \& mais progressos ate sua morte, \& canonização: representada na Universidade \& Collegio da Companhia de Jesu da Cidade da Evora, aos de Junho de 1622, Lisboa, Geraldo da Vinha, 1623.

Festas em Lisboa em 1622 (uma relação inédita), ed. Georg Schurhammer, Brotéria, 56, 1952, pp. 343-355.

Hsia, R. Po-chia, The World of Catholic Renewal, 1540-1770, Cambridge/New York, Cambridge University Press, 1998.

Osswald, Cristina, «lconografia das Cerimónias de Canonização no contexto português», Brotéria, 163, 2006, pp. 325-338.

- «El Ceremonial Barroco en las Fiestas de Canonización de Ignacio de Loyola y Francisco Javier (1622-1624)», en La Fiesta - Memoria del IV Encuentro Internacional sobre el Barroco «La Fiesta Barroca», ed. Norma Campos Vera, La Paz (Bolivia), Unión Latina, 2007, pp. 261-271.

Relação Geral das Festas que fez a Religiaõ da Companhia de Jesus na Prouincia de Portugal, na canonizaçaõ dos gloriosos Sancto Ignacio de Loyola seu fundador, \& S. Francisco Xavier Apostolo da India Oriental no anno de 1622, Lisboa, Pedro Craesbeeck, 1623.

Torres Olleta, M. Gabriela, Redes iconográficas: San Francisco Javier en la cultura visual del Barroco, Frankfurt am Main/Pamplona, Vervuert/Universidad de Navarra, 2009. 
